Open Access

\title{
Genome sequence and description of the anaerobic lignin-degrading bacterium Tolumonas lignolytica sp. nov.
}

\author{
Andrew F. Billings ${ }^{1}$, Julian L. Fortney ${ }^{2,3}$, Terry C. Hazen ${ }^{3,4,5}$, Blake Simmons ${ }^{2,6}$, Karen W. Davenport ${ }^{7}$, \\ Lynne Goodwin ${ }^{7}$, Natalia Ivanova ${ }^{8}$, Nikos C. Kyrpides ${ }^{8}$, Konstantinos Mavromatis $^{8}$, Tanja Woyke ${ }^{8}$ \\ and Kristen M. DeAngelis ${ }^{1 *}$
}

\begin{abstract}
Tolumonas lignolytica BRL6-1 ${ }^{\top} \mathrm{sp}$. nov. is the type strain of T. lignolytica sp. nov., a proposed novel species of the Tolumonas genus. This strain was isolated from tropical rainforest soils based on its ability to utilize lignin as a sole carbon source. Cells of Tolumonas lignolytica BRL6-1 ${ }^{\top}$ are mesophilic, non-spore forming, Gram-negative rods that are oxidase and catalase negative. The genome for this isolate was sequenced and returned in seven unique contigs totaling 3.6Mbp, enabling the characterization of several putative pathways for lignin breakdown. Particularly, we found an extracellular peroxidase involved in lignin depolymerization, as well as several enzymes involved in $\beta$-aryl ether bond cleavage, which is the most abundant linkage between lignin monomers. We also found genes for enzymes involved in ferulic acid metabolism, which is a common product of lignin breakdown. By characterizing pathways and enzymes employed in the bacterial breakdown of lignin in anaerobic environments, this work should assist in the efficient engineering of biofuel production from lignocellulosic material.
\end{abstract}

Keywords: Anaerobic lignin degradation, Tropical forest soil isolate, Tolumonas

\section{Introduction}

The exponential increase in anthropogenic greenhouse gas emissions following the industrial revolution has drastically affected the climate of Earth, inspiring the need to produce clean, renewable energy with the goal of mitigating the consequences of burning fossil fuels. Second generation biofuels are a promising source of sustainable energy because they are derived from lignocellulose, the most abundant natural polymer on Earth. However, this material is highly recalcitrant due to the occlusion of cellulose by lignin, and the microbial pathways for lignin degradation are not yet well understood.

Lignin is a complex aromatic heteropolymer present in the cell wall of all plants, and comprises $10-30 \%$ of cell wall material [1]. Lignin forms intricate associations with cellulose, the most abundant component within the cell wall, and serves as defense for plants, blocking access of cellulase enzymes to resist microbial breakdown.

\footnotetext{
* Correspondence: kristen@post.harvard.edu

${ }^{1}$ Microbiology Department, University of Massachusetts, Amherst, MA, USA Full list of author information is available at the end of the article
}

Consequently, the production of biofuels from plant biomass is physically and chemically hindered by lignin and its links to cellulose [1]. Aerobic lignin degradation has been extensively studied in fungi, suggesting that lignolytic extracellular peroxidase and laccase enzymes play a significant role in the mineralization of lignin in soil $[2,3]$. Recent studies focusing on bacterial breakdown and modification of lignin have found that members of the phylogenetic groups Alphaproteobacteria, Gammaproteobacteria, Firmicutes and Actinomycetes are major players in lignin degradation, in both soil and insect guts [4]. Among bacterial lignin or phenol degraders, Sphingomonas paucimobilis SYK-6 produces a $\beta$-aryl etherase [5], and Rhodococcus sp. RHA1 contains a $\beta$-ketoadipate pathway [6]; Kocuria and Staphylococcus also likely degrade aromatic compounds derived from lignocellulose [7]. Although many lignolytic bacteria grow in environments where oxygen is depleted [8], it has been suggested that they employ oxygen-requiring peroxidases, similar to the ones utilized by fungi [9]. 
To address the need for more efficient removal of the lignin portion of lignocellulose to streamline biofuel production, we isolated anaerobic bacteria from tropical rainforest soil in Puerto Rico. Humid tropical forest soils like those from the Long Term Ecological Research Station at the Luquillo Experimental Forest in Puerto Rico have been shown to have among the fastest rates of plant litter decomposition globally [10], despite their low and fluctuating redox potential [11]. Frequent episodes of anoxia at the Luquillo Forest inhibit fungal growth [12], suggesting that bacteria are responsible for the observed litter decomposition, and consequently providing an optimal environment for isolating bacteria involved in the anaerobic decomposition of plant litter, including cellulose and lignin compounds. Bacteria are more amenable to genetic modification than fungi and thus are more easily incorporated into biofuel processing technology, for instance through metabolic engineering. Additionally, bacteria capable of metabolizing lignin anaerobically are favorable to industrial biofuel production, considering that current technology relies on anaerobic digestors to process plant waste into biofuels [13]. With this in mind, we isolated and characterized a bacterium capable of anaerobic lignin degradation, Tolumonas lignolytica BRL6- ${ }^{\mathrm{T}}$ sp. nov., and provide a summary of its genome sequence and annotation.

\section{Organism information}

\section{Classification and features}

Tolumonas lignolytica BRL6-1 $1^{\mathrm{T}}$ was isolated from soil collected at the Bisley watershed site of the El Yunque National Forest in Puerto Rico, part of the Luquillo Experimental Forest in Luquillo, Puerto Rico, USA (Table 1; Additional file 1). Soils were diluted in water and used

Table 1 Classification and general features of Tolumonas lignolytica BRL6-1

\begin{tabular}{|c|c|c|c|}
\hline MIGS ID & Property & Term & Evidence code $^{a}$ \\
\hline & Classification & Domain Bacteria & $\operatorname{TAS}[45,46]$ \\
\hline & & Phylum Proteobacteria & TAS [47] \\
\hline & & Class Gammaproteobacteria & TAS [48] \\
\hline & & Order Aeromonadales & TAS [49] \\
\hline & & Family Aeromonadaceae & TAS $[50]$ \\
\hline & & Genus Tolumonas & TAS [51] \\
\hline & & Species Tolumonas lignolytica & \\
\hline & & Strain BRL6-1 ${ }^{\top}$ & \\
\hline & Gram stain & negative & IDA \\
\hline & Cell shape & rod & IDA \\
\hline & Motility & motile & IDA \\
\hline & Sporulation & non-sporulating & IDA \\
\hline & Temperature range & $15-37^{\circ} \mathrm{C}$ & IDA \\
\hline & Optimum temperature & $30^{\circ} \mathrm{C}$ & IDA \\
\hline & pH range; Optimum & $4.5-8.5 ; 7$ & \\
\hline & Carbon source & glucose, lactose, others (Table 6) & IDA \\
\hline MIGS-6 & Habitat & Tropical forest soil & TAS [52] \\
\hline MIGS-6.3 & Salinity & $1 \% \mathrm{NaCl}$ & IDA \\
\hline MIGS-22 & Oxygen requirement & Facultative aerobe & IDA \\
\hline MIGS-15 & Biotic relationship & Free-living & IDA \\
\hline MIGS-14 & Pathogenicity & Non-pathogenic & NAS \\
\hline MIGS-4 & Geographic location & $\begin{array}{l}\text { Soil collected from a subtropical lower montane wet forest } \\
\text { in the Luquillo Experimental Forest, part of the NSF- sponsored } \\
\text { Long-Term Ecological Research program in Puerto Rico }\end{array}$ & IDA \\
\hline MIGS-5 & Sample collection & July 2009 & IDA \\
\hline MIGS-4.1 & Latitude & $18.268 \mathrm{~N}$ & IDA \\
\hline MIGS-4.2 & Longitude & $65.760 \mathrm{~W}$ & IDA \\
\hline MIGS-4.4 & Altitude & $375 \mathrm{~m}$ & IDA \\
\hline
\end{tabular}

${ }^{a}$ Evidence codes - IDA Inferred from Direct Assay, TAS, Traceable Author Statement (i.e., a direct report exists in the literature), NAS Non-traceable Author Statement (i.e., not directly observed for the living, isolated sample, but based on a generally accepted property for the species, or anecdotal evidence). These evidence codes are from the Gene Ontology project [53] 
to inoculate anaerobic roll tubes containing a modified CCMA media consisting of $2.8 \mathrm{~g} \mathrm{~L}^{-1} \mathrm{NaCl}, 0.1 \mathrm{~g} \mathrm{~L}^{-1}$ $\mathrm{KCl}, 27 \mathrm{mM} \mathrm{MgCl}, 1 \mathrm{mM} \mathrm{CaCl}, 1.25 \mathrm{mM} \mathrm{NH}_{4} \mathrm{Cl}$, $9.76 \mathrm{~g} \mathrm{~L}^{-1} \mathrm{MES}, 1.1 \mathrm{ml} \mathrm{L}^{-1} \mathrm{~K}_{2} \mathrm{HPO}_{4}, 12.5 \mathrm{ml} \mathrm{L}^{-1}$ trace minerals [14, 15], and $1 \mathrm{ml} \mathrm{L}^{-1}$ Thauer's vitamins [16], with alkali lignin added as the sole source of carbon. Tubes were incubated at ambient temperature for 3 months before colonies were picked and characterized.

Tolumonas lignolytica BRL6-1 ${ }^{\mathrm{T}}$ cells are Gramnegative, facultative rods capable of growth from 15 to $37^{\circ} \mathrm{C}$ and $\mathrm{pH} 4.5-8.5$ (Fig. 1). Colonies on $10 \%$ Tryptic Soy Agar (TSA) plates appear as white, flat circles with opaque centers and translucent halos.

Sanger sequencing was performed on the small subunit ribosomal RNA (16S rRNA) gene using universal primers 27F and 1492R [17]. BLAST analysis shows $97 \%$ identity to the full length $16 \mathrm{~S}$ rRNA gene of Tolumonas auensis type strain TA 4, indicating BRL6- $1^{\mathrm{T}}$ as a potentially novel species of the Tolumonas genus, within the Aeromonadaceae family of the Gammaproteobacteria (Fig. 2a). Since the 16S rRNA gene sequence is not sufficient to clearly define the evolutionary history of this cluster of the Gammaproteobacteria, a hierarchical clustering of whole genomes based on COGS was constructed [18] (Fig. 2b). This clustering supports the placement of T. lignolytica BRL6-1 ${ }^{\mathrm{T}}$ as a novel species within the Tolumonas genus.

\section{Genome sequencing information}

\section{Genome project history}

Tolumonas lignolytica BRL6-1 ${ }^{\mathrm{T}}$ was selected for sequencing based on its ability to utilize lignin as a sole carbon

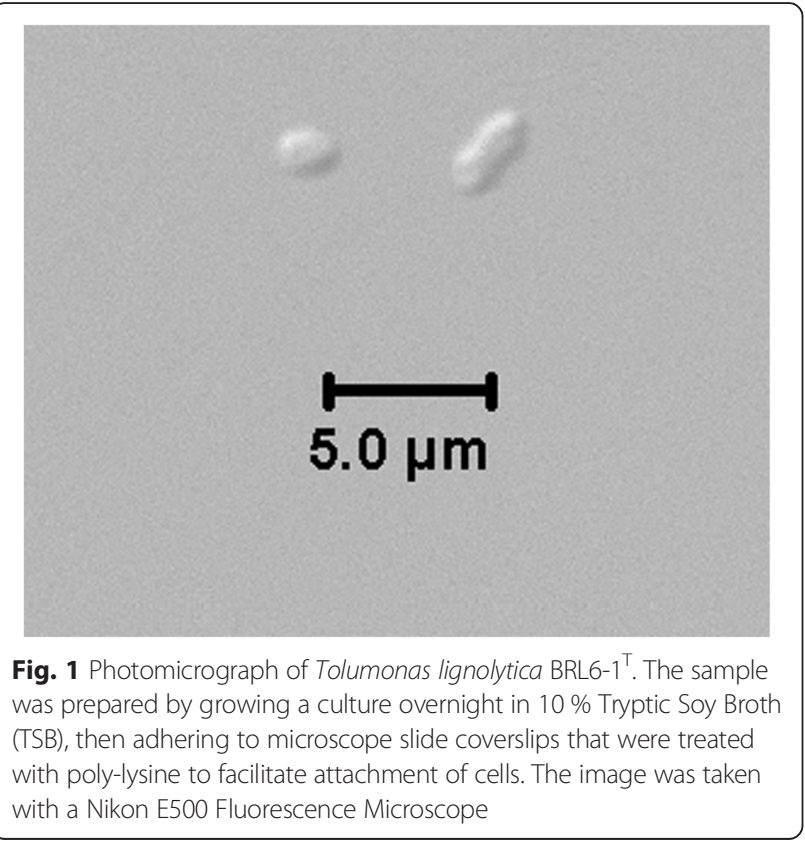

source. Genome sequencing was performed by the JGI and completed on February 22, 2013 and the genome was presented for public access on IMG M/ER on August 28, 2013. Table 2 presents the project information and its association with MIGS version 2.0 compliance [19].

\section{Growth conditions and genomic DNA preparation}

For genomic DNA extraction, strain BRL6- $1^{\mathrm{T}}$ was grown overnight in $10 \% \mathrm{TSB}$ at $30{ }^{\circ} \mathrm{C}$ with shaking at $225 \mathrm{rpm}$. Genomic DNA for sequencing was obtained following a modified cetyl-trimethylammonium bromide (CTAB) extraction protocol established by the DOE Joint Genome Institute. Modifications were as follows: 1) Overnight cultures were resuspended to an OD@600 nm of 0.5, instead of 1.0; 2) Lysozyme incubation was carried out at $37{ }^{\circ} \mathrm{C}$ for $30 \mathrm{~min}$; 3) Proteinase $\mathrm{K}$ incubation was carried out for $3 \mathrm{~h}$; 4 ) the concentration of Proteinase $\mathrm{K}$ was doubled. The extracted DNA was quantified using the Invitrogen ${ }^{\mathrm{nx}}$ Quant-i $^{\mathrm{m}}$ PicoGreen $^{\circ}$ dsDNA Assay Kit and measured using the PicoGreen Fluorescence protocol on the SpectraMax M2 Microplate Reader by Molecular Devices. Genomic DNA samples were verified as strain BRL6- $1^{\mathrm{T}}$ via $16 \mathrm{~S}$ rRNA gene sequencing before being shipped to JGI for genome sequencing.

\section{Genome sequencing and assembly}

The draft genome of strain BRL6-1 ${ }^{\mathrm{T}}$ was generated at the DOE Joint Genome Institute using both Illumina and Pacific Biosciences (PacBio) technologies. An Illumina standard shotgun library and long insert mate pair library was constructed and sequenced using the Illumina HiSeq 2000 platform [20]. 64,682,509 reads totaling 9702.4 $\mathrm{Mb}$ were generated from the standard shotgun and 45,878,643 reads totaling 4175.0 $\mathrm{Mb}$ were generated from the long insert mate pair library. A Pacbio SMRTbell ${ }^{\text {Tw }}$ library was constructed and sequenced on the PacBio RS platform. 41,131 raw PacBio reads yielded 41,162 adapter-trimmed and quality filtered subreads totaling 118.4 $\mathrm{Mb}$. All raw Illumina sequence data was passed through DUK, a filtering program developed at JGI, which removes known Illumina sequencing and library preparation artifacts [21]. Filtered Illumina and PacBio reads were assembled using AllpathsLG as previously described [22]. The total size of the genome is 3.6 $\mathrm{Mb}$. The final draft assembly contained 9 contigs in 9 scaffolds, and was based on 9669.4 Mb of Illumina Std PE, 4174.1 Mb of Illumina CLIP PE and 118.4 Mb of PacBio post filtered data, which provides an average 3837X Illumina coverage and 32.8X PacBio coverage of the genome, respectively. 


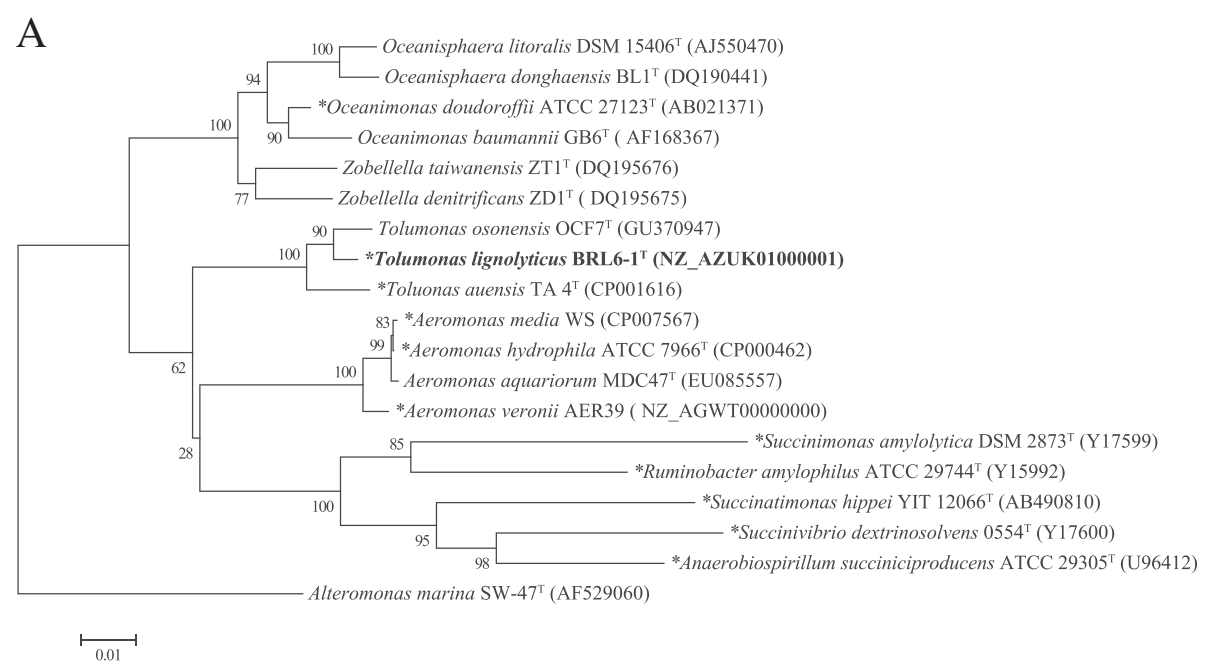

$\mathrm{B}$

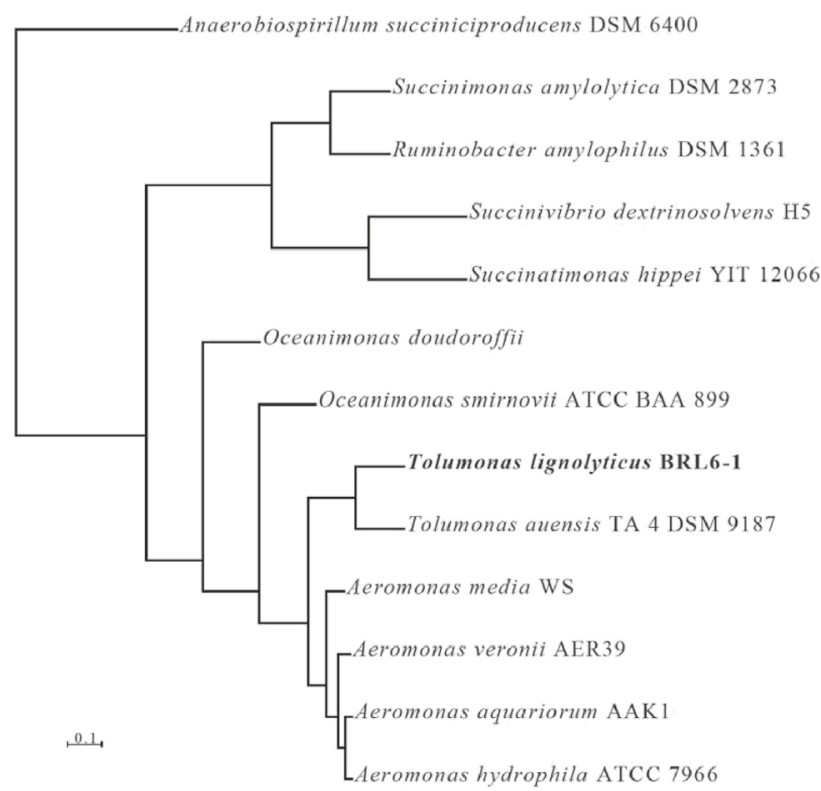

Fig. 2 Phylogenetic tree highlighting the position of Tolumonas lignolytica BRL6-1 ${ }^{\top}$ among the Aeromonadales. a The phylogenetic tree based on 165 ribosomal RNA gene sequence was inferred using the Neighbor-Joining method [54] within MEGA6 [55]. Bootstrap values of 1000 replicate trees are shown at the branches [56]. The tree is drawn to scale, with branch lengths in the same units as those of the evolutionary distances used to infer the phylogenetic tree. The evolutionary distances were computed using the Jukes-Cantor method [57] and are in units of the number of base substitutions per site. All positions containing gaps and missing data were eliminated, creating a total of 1234 positions in the final dataset. GenBank accession numbers are shown in parentheses after strain numbers. Type strains are indicated with a superscript T. Organisms with genomes available are indicated by an asterisk before the name. $\mathbf{b}$ Whole genomes were hierarchically clustered based on COG profiles using tools in IMG [58]. T. lignolytica BRL6-1 ${ }^{\top}$ is indicated in bold in both phylogenetic trees

\section{Genome annotation}

Genes were identified using Prodigal [23], followed by a round of manual curation using GenePRIMP [24]. The predicted CDSs were translated and used to search the National Center for Biotechnology Information nonredundant database, UniProt, TIGRFam, Pfam, KEGG, COG, and InterPro databases. The tRNAScanSE tool [25] was used to find tRNA genes, whereas ribosomal RNA genes were found by searches against models of the ribosomal RNA genes built from SILVA [26]. Other non-coding RNAs such as the RNA components of the protein secretion complex and the RNase P were identified by searching the genome for the corresponding Rfam profiles using INFERNAL [27]. Additional gene prediction analysis and manual functional annotation was performed within the Integrated Microbial Genomes (IMG) platform [28] developed by the Joint Genome Institute, Walnut Creek, CA, USA [29]. 
Table 2 Sequencing project information

\begin{tabular}{|c|c|c|}
\hline MIGS ID & Property & Term \\
\hline MIGS-31 & Finishing quality & High-quality draft \\
\hline MIGS-28 & Libraries used & $\begin{array}{l}\text { Three libraries: Illumina std shotgun } \\
\text { library, Illumina long insert mate pair } \\
\text { library, Pacbio SMRTbel|TM library }\end{array}$ \\
\hline MIGS-29 & $\begin{array}{l}\text { Sequencing } \\
\text { platforms }\end{array}$ & Illumina HiSeq 2000, PacBio RS \\
\hline $\begin{array}{l}\text { MIGS- } \\
31.2\end{array}$ & Fold coverage & $2680 X, 1157 X, 33 X$ \\
\hline MIGS-30 & Assemblers & AllpathsLG \\
\hline \multirow[t]{6}{*}{ MIGS-32 } & Gene calling method & Prodigal, GenePRIMP \\
\hline & Locus Tag & $\mathrm{H} 027$ \\
\hline & GenBank ID & AZUK00000000.1 \\
\hline & $\begin{array}{l}\text { GenBank Date of } \\
\text { Release }\end{array}$ & May 23, 2014 \\
\hline & GOLD ID & Gi0037033 \\
\hline & BIOPROJECT & PRJNA186459 \\
\hline \multirow[t]{2}{*}{ MIGS-13 } & $\begin{array}{l}\text { Source Material } \\
\text { Identifier }\end{array}$ & In submission \\
\hline & Project relevance & Biofuels, Environmental \\
\hline
\end{tabular}

\section{Genome properties}

One chromosomal origin of replication, located at position 1,760,186-1,760,733 bp of contig 1 was identified, suggesting that the genome contains only one chromosome of at least 3.187Mbp (Fig. 3). The location was determined using the Z-curve method [30-32], which utilizes base pair disparities to create a unique threedimensional graph of the genome using Ori-Finder software [33]. Although nine contigs are presented in the GenBank record (for the genome AZUK00000000.1), contigs 5 and 9 were direct repeats of sequences contained in the other contigs, so we hypothesized that they are repeated scaffolds and excluded them from our analyses (Table 3 ). Due to remarkably high repeat content at the ends of contigs, we were unable to close the gaps between them using regular sequencing methods. The contigs may be part of the chromosome, but a plasmid extraction indicated the presence of at least one plasmid. A search through the PATRIC database of plasmid sequences shows that contigs $2-8$, excluding 5 , all have homology to known plasmid sequences, using maximum E-value of $1 \mathrm{e}^{-5}$ [34]. Furthermore, contigs $3,4,7$, and 8 have annotated genes commonly found in plasmids, such as toxin-antitoxin sequences, prevent-host-death

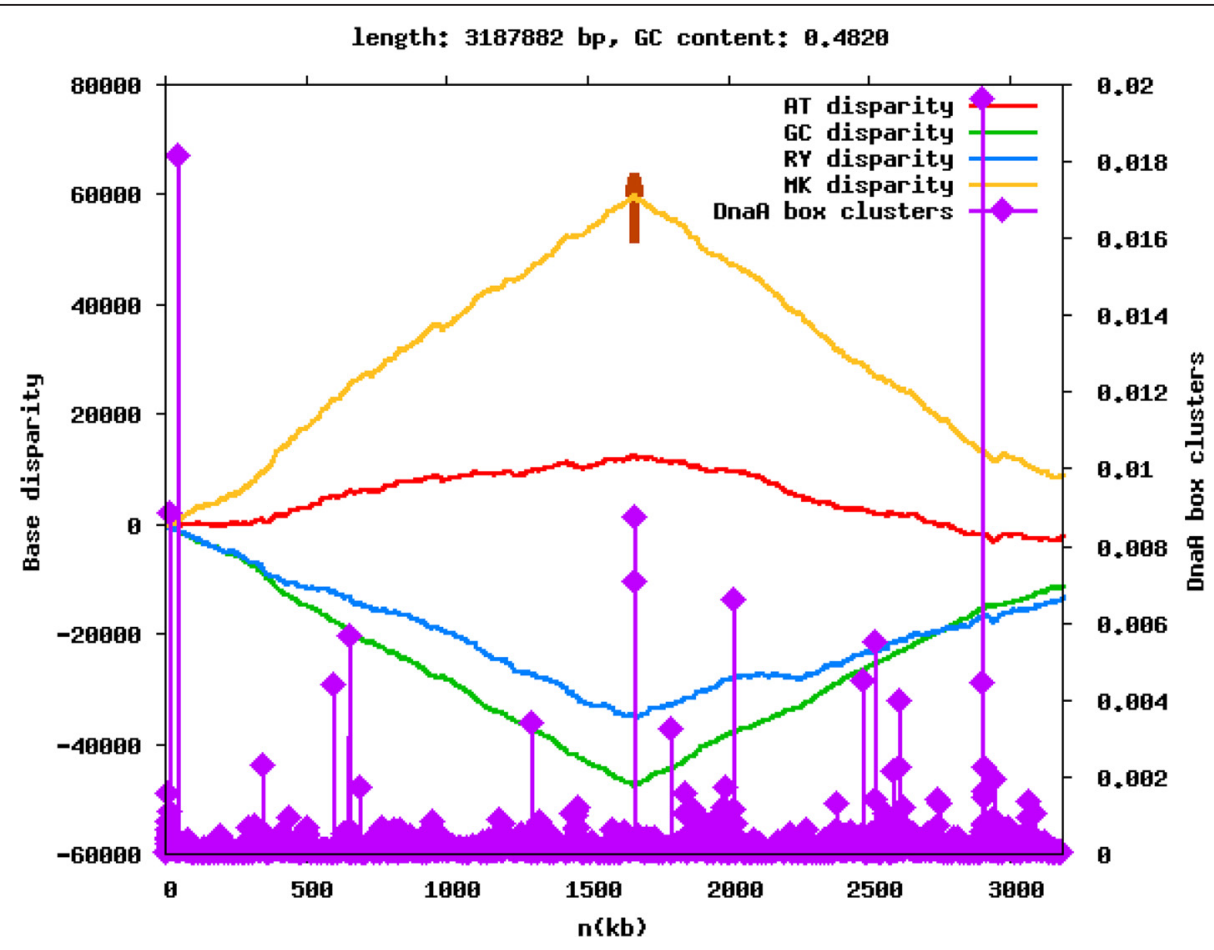

Fig. 3 Z-curve graph of T. lignolytica BRL6-1 ${ }^{\top}$ contig 1. The Z-curve graph was made using Ori-Finder software. The sequence is rotated such that the beginning and ending are the maximum of the GC disparity curve. The short vertical red line indicates the location of the indicator gene dnaA, while purple peaks with diamonds indicate DnaA box clusters. The shift in base pair disparity coincides with the location of the dnaA gene and a large cluster of DnaA boxes, which together strongly suggest the location of the origin of replication. MK disparity represents the ratio of amino (A,C) to keto $(G, T)$ bases, while RY disparity represents the ratio of purine $(A, G)$ to pyrimidine $(C, T)$ bases. Finally, the AT and $G C$ disparities represent the ratio of weak to strong hydrogen bond forming bases, respectively 
Table 3 Summary of genome: one chromosome and six other contigs

\begin{tabular}{llll}
\hline Label & Size $(\mathrm{kb})$ & Topology & INSDC identifier \\
\hline Chromosome 1 & 3187 & linear & AZUK01000001 \\
Contig 2 & 316 & linear & AZUK01000002 \\
Contig 3 & 44 & linear & AZUK01000003 \\
Contig 4 & 24 & linear & AZUK01000004 \\
Contig 6 & 12 & linear & AZUK01000006 \\
Contig 7 & 11 & linear & AZUK01000007 \\
Contig 8 & 10 & linear & AZUK01000008 \\
\hline
\end{tabular}

family sequences, and plasmid maintenance and stabilization protein genes, making them likely candidates.

Of the 3427 predicted genes, 3323 were identified as protein-encoding genes, while 131 RNA genes were found. Of the total protein coding genes identified, $75.02 \%$ were assigned to a putative function. The properties and the statistics of the genome are summarized in Tables 3, 4 and 5 .

\section{Insights from the genome sequence \\ Genome to genome comparisons}

Once the genome of strain BRL6- ${ }^{\mathrm{T}}$ was sequenced, we were able to compare it to the genome of $T$. auensis, its closest relative. The two genomes have an average nucleotide identity (ANI) of $84 \%$, far below the $95 \%$ threshold for species delineation [35]. A tool developed by DSMZ called the genome to genome distance calculator (GGDC) compares genome sequences to databases

Table 4 Nucleotide content and gene count levels of the genome

\begin{tabular}{llr}
\hline Attribute & Value & \% of total \\
\hline Genome size (bp) & $3,607,052$ & 100.00 \\
DNA coding (bp) & $3,268,621$ & 89.99 \\
DNA G+C (bp) & $1,715,377$ & 47.56 \\
DNA scaffolds & 7 & 100.00 \\
Total genes & 3427 & 100.00 \\
Protein coding genes & 3296 & 96.18 \\
RNA genes & 131 & 3.82 \\
Pseudo genes & 24 & 0.70 \\
Genes in internal clusters & 2431 & 70.94 \\
Genes with function prediction & 2571 & 75.02 \\
Genes assigned to COGs & 2797 & 81.62 \\
Genes with Pfam domains & 2916 & 85.09 \\
Genes with signal peptides & 273 & 7.97 \\
Genes with transmembrane helices & 755 & 22.03 \\
CRISPR repeats & 1 & - \\
\hline
\end{tabular}

The total is based on either the size of the genome in base pairs or the total number of protein coding genes in the annotated genome
Table 5 Number of genes associated with COG functional categories

\begin{tabular}{|c|c|c|c|}
\hline Code & Value & $\begin{array}{l}\% \\
\text { age }\end{array}$ & Description \\
\hline J & 168 & 5.10 & Translation, ribosomal structure and biogenesis \\
\hline A & 1 & 0.03 & RNA processing and modification \\
\hline K & 217 & 6.58 & Transcription \\
\hline L & 129 & 3.91 & Replication, recombination and repair \\
\hline B & 0 & $0.00 \mathrm{~s}$ & Chromatin structure and dynamics \\
\hline D & 35 & 1.06 & $\begin{array}{l}\text { Cell cycle control, cell division, chromosome } \\
\text { partitioning }\end{array}$ \\
\hline V & 37 & 1.12 & Defense mechanisms \\
\hline $\mathrm{T}$ & 171 & 5.19 & Signal transduction mechanisms \\
\hline M & 159 & 4.82 & Cell wall/membrane biogenesis \\
\hline N & 112 & 3.40 & Cell motility \\
\hline U & 88 & 2.67 & Intracellular trafficking and secretion \\
\hline O & 106 & 3.22 & $\begin{array}{l}\text { Posttranslational modification, protein turnover, } \\
\text { chaperones }\end{array}$ \\
\hline C & 176 & 5.34 & Energy production and conversion \\
\hline G & 247 & 7.49 & Carbohydrate transport and metabolism \\
\hline E & 241 & 7.31 & Amino acid transport and metabolism \\
\hline $\mathrm{F}$ & 73 & 2.21 & Nucleotide transport and metabolism \\
\hline H & 144 & 4.37 & Coenzyme transport and metabolism \\
\hline । & 50 & 1.52 & Lipid transport and metabolism \\
\hline$P$ & 126 & 3.82 & Inorganic ion transport and metabolism \\
\hline Q & 31 & 0.94 & $\begin{array}{l}\text { Secondary metabolites biosynthesis, transport } \\
\text { and catabolism }\end{array}$ \\
\hline $\mathrm{R}$ & 259 & 7.86 & General function prediction only \\
\hline S & 245 & 7.43 & Function unknown \\
\hline- & 930 & 28.21 & Not in COGs \\
\hline
\end{tabular}

The total is based on the total number of protein coding genes in the annotated genome

of DNA-DNA hybridization (DDH) data [36]. It estimates the $\mathrm{DDH}$ between these two genomes to be $23.10 \%+/-2.37$, again far below the species threshold (70\%). The GGDC also uses logistic regression to estimate the probability that $\mathrm{DDH}>70 \%$, i.e. the two genomes belong to the same species. The GGDC calculated a $<0.01 \%$ chance that DDH $>70 \%$ between the genomes of strain BRL6- $1^{\mathrm{T}}$ and T. auensis. These data support the assertion that strain BRL6- $1^{\mathrm{T}}$ is a novel species.

\section{Oxidative enzymes}

To facilitate physiological comparisons among the species within the Tolumonas genus, T. auensis and T. osonensis were acquired from the DSMZ culture collection in Germany. Oxidase tests confirmed that all three Tolumonas species, including Tolumonas lignolytica BRL6$1^{\mathrm{T}}$, are negative for oxidation of cytochrome $\mathrm{c}$, as 


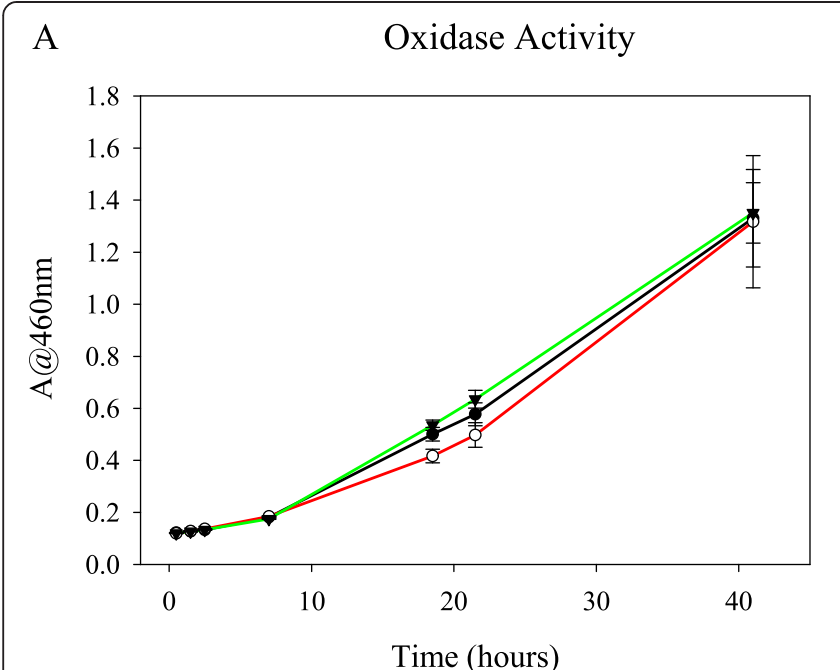

B

Peroxidase Activity

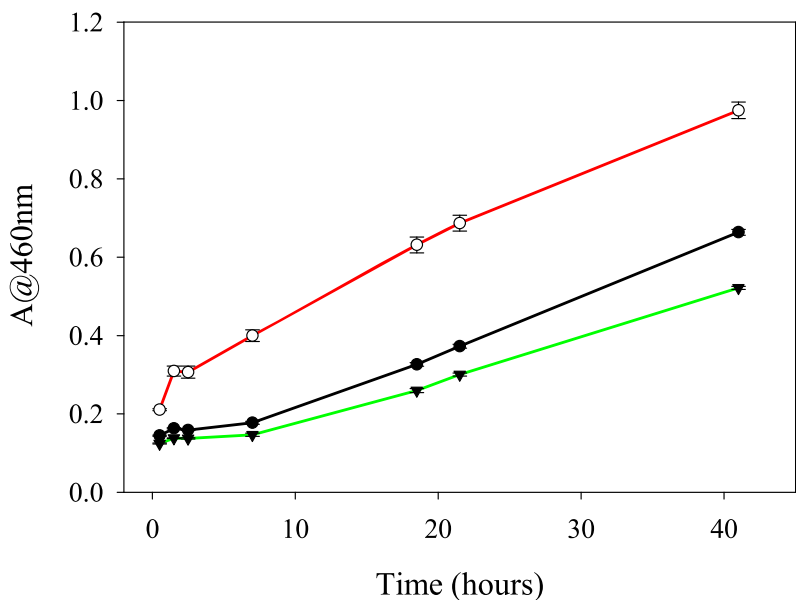

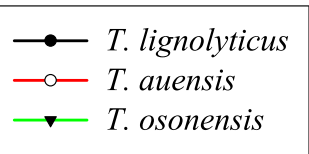

Fig. 4 Oxidase and peroxidase enzyme activity for three Tolumonas organisms. Oxidative enzyme assays were performed by incubating isolates in nutrient broth with $25 \mathrm{mM} \mathrm{L-DOPA}$. Peroxidase enzyme assays were performed in the same manner, with the addition of $3 \%$ hydrogen peroxide. A negative control without inoculum was also measured and subtracted from experimental values

Table 6 Carbon sources utilized by Tolumonas lignolytica BRL6-1 ${ }^{\top}$ anaerobically

\begin{tabular}{ll}
\hline Carbon source & Omnilog units \\
\hline D-Trehalose & 168 \\
L-Arabinose & 166 \\
D-Fructose & 164 \\
D-Sorbitol & 161 \\
D-Gluconic Acid & 161 \\
a-D-Glucose & 161 \\
Maltotriose & 156 \\
N-Acetyl-D-Glucosamine & 145 \\
Sucrose & 131 \\
D-Galactose & 128 \\
Tween 20 & 128 \\
Maltose & 128 \\
D-Mannose & 108 \\
Tween 40 & 106 \\
D-Melibiose & 102 \\
D-Mannitol & 95 \\
D-Ribose & 91 \\
Tween 80 & 62 \\
L-Lyxose & 36 \\
\hline
\end{tabular}

colonies did not change color when applied to BD BBL ${ }^{\mathrm{mu}}$ DrySlide $^{\text {rm }}$ test strips. However, oxidative enzyme assays show that all three organisms are capable of oxidizing 3,4-dihydroxy-L-phenylalanine (L-DOPA), a compound that is utilized as a lignin analog (Fig. 4a).

A catalase test was performed on each Tolumonas organism by dropping $3 \%$ hydrogen peroxide on cultures that had incubated at $30{ }^{\circ} \mathrm{C}$ for $20 \mathrm{~h}$. T. lignolytica and $T$. auensis had very weak positive reactions, while T. osonensis exhibited a much stronger phenotype. However, all three organisms showed relatively strong peroxidase enzyme activity (Fig. 4B). A search through the genomes of $T$. auensis and T. lignolytica shows that both organisms possess just one copy of the same enzyme with putative catalase activity (EC:1.11.1.21), while each genome contains several peroxidase genes. T. osonensis does not have its genome sequenced and thus we could not search for catalase or peroxidase genes.

Table 7 Carbon sources differentially utilized by Tolumonas species anaerobically

\begin{tabular}{llll}
\hline Carbon source & T. auensis & T. osonensis & T. lignolytica \\
\hline D-Arabinose & + & - & + \\
D-Lactose & - & + & + \\
D-Xylose & - & - & + \\
Glycerol & - & - & + \\
Fumarate & - & + & - \\
Pyruvate & - & + & - \\
\hline
\end{tabular}


Table 8 Enzymes involved in lignin degradation with homologues in BRL6-1 ${ }^{\top}$ genome

\begin{tabular}{|c|c|c|c|c|c|}
\hline Enzyme & $\begin{array}{l}\text { Gene } \\
\text { name }\end{array}$ & Characterized in & $\begin{array}{l}\text { \# of copies } \\
\text { in genome }\end{array}$ & E value & Gene annotation in BRL6-1 $1^{\top}$ genome \\
\hline $\begin{array}{l}\text { Ca-dehydrogenase involved in b-aryl } \\
\text { ether cleavage }\end{array}$ & $\operatorname{lig} D$ & Sphingomonas paucimobilis SYK-6 & 2 & $6 e-12 ; 4 e-10$ & $\begin{array}{l}\text { 1)3-oxoacyl-[acyl-carrier-protein] reductase } \\
\text { (EC 1.1.1.100)2)hypothetical protein }\end{array}$ \\
\hline Beta-etherase & ligF & Sphingomonas paucimobilis SYK-6 & 1 & $4 e-11$ & Glutathione S-transferase \\
\hline Feruloyl-CoA synthetase & fCS & Pseudomonas putida strain KT2440 & 1 & $1 e-10$ & Acyl-CoA synthetases (AMP-forming)/AMP-acid ligases II \\
\hline Feruloyl-CoA hydratase/lyase & ferB & Sphingomonas paucimobilis & 1 & $7 e-15$ & 1,4-Dihydroxy-2-naphthoyl-CoA synthase (EC 4.1.3.36) \\
\hline Feruloyl-CoA hydratase/lyase & ferB2 & Sphingomonas paucimobilis & 1 & $3 e-32$ & 1,4-Dihydroxy-2-naphthoyl-CoA synthase (EC 4.1.3.36) \\
\hline Vanillin dehydrogenase & ligV & Sphingomonas paucimobilis & 5 & $\begin{array}{l}4 e-66 ; 3 e-65 ; 2 e-62 ; \\
2 e-35 ; 8 e-08\end{array}$ & $\begin{array}{l}\text { 1) succinate semialdehyde dehydrogenase (EC 1.2.1.16) } \\
\text { 2) gamma-glutamyl-gamma-aminobutyraldehyde } \\
\text { dehydrogenase } \\
\text { 3) NAD-dependent aldehyde dehydrogenases } \\
\text { 4) succinylglutamic semialdehyde dehydrogenase } \\
\text { (EC 1.2.1.71) } \\
\text { 5) acetaldehyde dehydrogenase (EC 1.2.1.10)/alcohol } \\
\text { dehydrogenase AdhE (EC 1.1.1.1) }\end{array}$ \\
\hline Vanillate O-demethylase oxidoreductase & $\operatorname{vanB}$ & $\begin{array}{l}\text { Pseudomonas syringae pv. tomato } \\
\text { strain DC3000 }\end{array}$ & 3 & $9 e-18 ; 7 e-14 ; 9 e-12$ & $\begin{array}{l}\text { 1) Hemoglobin-like flavoprotein2)Flavodoxin reductases } \\
\text { (ferredoxin-NADPH reductases) family 13)Predicted } \\
\text { ferric reductase }\end{array}$ \\
\hline 3-carboxymuconate cycloisomerase & pcaB & Pseudomonas putida & 2 & $9 e-13 ; 5 e-09$ & $\begin{array}{l}\text { 1)Adenylosuccinate lyase (EC 4.3.2.2)2)argininosuccinate } \\
\text { lyase (EC 4.3.2.1) }\end{array}$ \\
\hline 4-carboxymuconolactone decarboxylase & $\mathrm{pcaC}$ & Pediococcus acidilactici D3 & 3 & 6e-30; 7e-27; 1e-06 & $\begin{array}{l}\text { Uncharacterized homolog of gamma-carboxymuconolactone } \\
\text { decarboxylase subunit (all 3) }\end{array}$ \\
\hline B-ketoadipate enol-lactone hydrolase & $\mathrm{pcaD}$ & Acinetobacter baumannii strain SDF & 2 & $5 e-15 ; 5 e-13$ & $\begin{array}{l}\text { 1) carboxylesterase BioH (pimeloyl-CoA synthesis) } \\
\text { (EC 3.1.1.85)2)Predicted hydrolases or acyltransferases } \\
\text { (alpha/beta hydrolase superfamily) }\end{array}$ \\
\hline
\end{tabular}

Enzyme protein sequences were obtained from UniProt. E values are based on blastp results performed in img/er against the T. lignolytica BRL6-1 ${ }^{\top}$ genome 


\section{Carbon utilization}

Based on the genome sequence of T. lignolytica BRL6$1^{\mathrm{T}}$, we expected that this organism would be able to easily utilize fructose, glucose, mannitol, sorbitol, sucrose, and trehalose, as there are phosphotransferase system (PTS) genes annotated specifically for these carbon sources. Biolog phenotypic arrays were used to test the carbon sources utilized by strain BRL6- ${ }^{\mathrm{T}}$ under anaerobic conditions, using a modified version of DSMZ medium 500 (referred to as $\mathrm{mGV}$ medium), in which $\mathrm{FeSO}_{4} \cdot 7 \mathrm{H}_{2} \mathrm{O}, \mathrm{Na}_{2} \mathrm{~S} \cdot 9 \mathrm{H}_{2} \mathrm{O}$, yeast extract, and the selenite/tungstate solution were omitted. Plates were performed in duplicate, and reactions were only considered positive if the difference between average and standard error was greater than 20 units. Our results indicated that out of the 96 carbon sources tested, strain BRL6-1 ${ }^{\mathrm{T}}$ was able to utilize 26 under anaerobic conditions (Table 6), included the carbon sources predicted based on the genome sequence. Summarized in Table 7 are carbon sources that are differentially utilized among the three Tolumonas organisms under anaerobic conditions [37, 38].

We predicted that lactose fermentation would be possible in strain BRL6-1 ${ }^{\mathrm{T}}$, as the genome contains four copies of PTS system genes specific to lactose, more than for any other carbon source. T. lignolytica BRL6-1 ${ }^{\mathrm{T}}$ grows well on aerobic plates of eosin methylene blue agar (EMB) medium, and produces metallic green colonies after 2 days incubation, suggesting aggressive lactose fermentation, a common characteristic of members of the Enterobacteriaceae family. Considering that enteric bacteria are common inhabitants of soils [39], it is plausible that this phenotype originated from horizontal gene transfer. The type strains of $T$. auensis and T. osonensis were able to grow slowly on aerobic EMB plates, but did not produce metallic green colonies. Therefore, EMB plate growth morphology can be used to easily distinguish T. lignolytica BRL6-1 ${ }^{\mathrm{T}}$ from the other Tolumonas species.

\section{Lignocellulose degradation}

The genome of Tolumonas lignolytica BRL6-1 $1^{\mathrm{T}}$ contains four putative peroxidase genes, which may be important in depolymerizing lignin in the environment [40]. The genome also contains homologues to ligD and ligF, genes characterized in Sphingomonas paucimobilis SYK-6 [41] that encode enzymes responsible for the cleavage of $\beta$ aryl ether bonds. This type of bond comprises approximately $50 \%$ of the linkages among lignin monomers [9], thus its cleavage is crucial to lignocellulose breakdown. Furthermore, strain BRL6- $1^{\mathrm{T}}$ possesses homologues to genes involved in the pathway for transforming ferulic acid, a common lignin breakdown product, into vanillate,

Tolumonas BRL6-1 in mGV Medium

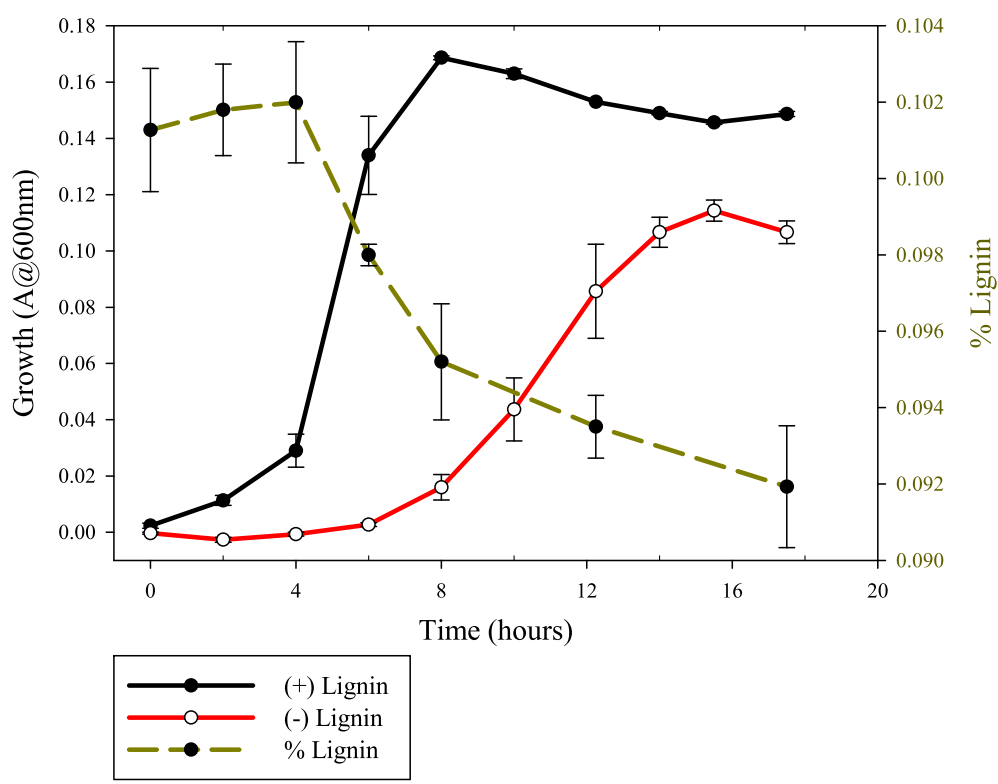

Fig. 5 Growth curve of Tolumonas lignolytica BRL6-1 ${ }^{\top}$ in mGV medium. Solid lines depict the growth (left axis) of the organism with and without lignin amendment, with error bars showing the standard error of triplicate samples. The dashed line shows lignin concentration (right axis) throughout the growth curve. Lignin concentration was measured by removing $1 \mathrm{ml}$ of culture from anaerobic septum bottles, diluting 1:10 in distilled water, filtering out cells, then measuring the absorbance at $310 \mathrm{~nm}$. These values were compared to a standard curve of known concentrations of lignin in mGV medium measured at this wavelength 
then into protocatechuate, and finally to $\beta$-ketoadipate (summarized in Table 8) [42, 43].

The genome also contains several cytochrome oxidase genes, which may be implicated in utilizing lignin as an electron acceptor for dissimilatory respiration, as was observed for 'gnolyticus' SCF1 [40], an organism that was obtained in the same isolation effort as BRL6- $1^{\mathrm{T}}$ [44]. Preliminary data supporting this hypothesis can be seen in Fig. 5, which depicts the growth of strain BRL6$1^{\mathrm{T}}$ in a further simplified version of mGV medium (in which resazurin, sodium bicarbonate, and cysteine were also omitted from the recipe), with $0.2 \%$ glucose supplied as a readily oxidized carbon source. The addition of lignin in the media increased both the growth rate and the maximum optical density achieved by strain BRL6- $1^{\mathrm{T}}$. Additionally, a decrease in lignin concentration correlates to exponential growth phase, suggesting that BRL6- $1^{\mathrm{T}}$ is using lignin as an additional carbon source, and/or as an electron acceptor, which may enhance the organism's ability to utilize the more labile glucose as a carbon source.

\section{Conclusions}

Based on biochemical characterization and genome analysis, we formally propose the creation of Tolumonas lignolytica sp. nov., of which BRL6-1 $1^{\mathrm{T}}$ is the type strain. Its 3.6 Mbp genome contains a suite of genes coding proteins involved in the breakdown of lignocellulosic material. These characteristics highlight its applicability to the industrial production of biofuels from plant biomass.

\section{Description of Tolumonas lignolytica sp. nov.}

TolumonasL. n. lignum, wood, lignin; Gr. Adj. lytikos, loosening, dissolving; NL fem adj. lignolytia, splitting lignin, referring to the ability to breakdown lignin).

The cells of type strain BRL6- $1^{\mathrm{T}}$ are Gram-negative rods that are oxidase and catalase negative. Colonies on $10 \%$ TSA plates are flat white circles with opaque centers and characteristic translucent halos. Growth occurs at $15-37{ }^{\circ} \mathrm{C}$ with an optimum at $30{ }^{\circ} \mathrm{C}$. The optimum $\mathrm{pH}$ is 7 , and cells can tolerate up to $1 \% \mathrm{NaCl}$. Grows well aerobically and anaerobically. The following carbon sources support anaerobic growth: d-trehalose, l-arabinose, d-fructose, d-sorbitol, d-gluconic acid, a$\mathrm{d}$-glucose, maltotriose, n-acetyl-d-glucosamine, sucrose, d-galactose, Tween 20, maltose, d-mannose, Tween 40, d-melibiose, d-mannitol, d-ribose, Tween 80, 1-lyxose.

The $\mathrm{G}+\mathrm{C}$ content of the genome is $47.56 \%$. The type strain BRL6- $1^{\mathrm{T}}$ (=DSM $100457=$ ATCC $[$ in submission]) was isolated from tropical rainforest soil using lignin as the sole carbon source.

\section{Additional file}

Additional file 1: Table S1. Associated MIGS record. (DOC 74 kb)

\section{Abbreviations}

RDP: Ribosomal Database Project (East Lansing, MI, USA); CDS: Coding sequences; JGl: Joint Genome Institute (Walnut Creek, CA, USA).

\section{Competing interests}

The authors declare no competing interests.

\section{Authors' contributions}

AFB and JLF performed the microbiology and molecular biology studies; KFD, LG, NI, KCK, KM, and TW performed the sequencing and annotation; AFB and KMD performed the genomic analysis; AFB, TCH, BAS and KMD wrote the manuscript. All authors read and approved the final manuscript.

\section{Acknowledgements}

The work conducted in part by the U.S. Department of Energy Joint Genome Institute and in part by the Joint BioEnergy Institute (http://www.jbei.org), and is supported by the Office of Science of the U.S. Department of Energy Under Contract No. DE-AC02-05CH11231.

\section{Author details}

${ }^{1}$ Microbiology Department, University of Massachusetts, Amherst, MA, USA. ${ }^{2}$ Microbial Communities Group, Deconstruction Division, Joint BioEnergy Institute, Emeryville, CA, USA. ${ }^{3}$ Department of Civil \& Environmental Engineering, The University of Tennessee, Knoxville, TN, USA. ${ }^{4}$ Department of Microbiology, The University of Tennessee, Knoxville, TN, USA. ${ }^{5}$ Department of Earth \& Planetary Sciences, The University of Tennessee, Knoxville, TN, USA. ${ }^{6}$ Sandia National Lab, Livermore, CA, USA. ${ }^{7}$ Los Alamos National Laboratory, Los Alamos, NM, USA. ${ }^{8}$ Department of Energy Joint Genome Institute, Walnut Creek, CA, USA.

Received: 2 March 2015 Accepted: 10 November 2015

Published online: 19 November 2015

\section{References}

1. Wei H, Xu Q, Taylor II LE, Baker JO, Tucker MP, Ding S-Y. Natural paradigms of plant cell wall degradation. Curr Opin Biotechnol. 2009;20:330-8.

2. Freeman $\mathrm{C}$, Ostle N, Kang H. An enzymic "latch" on a global carbon store. Nature. 2001;409:149.

3. Paul EA, Clark FE. Soil microbiology, ecology, and biochemistry. Fort Collins, CO USA: Academic Press; 1996.

4. Bugg TDH, Ahmad M, Hardiman EM, Singh R. The emerging role for bacteria in lignin degradation and bio-product formation. Curr Opin Biotechnol. 2011;22:394-400.

5. Masai E, Katayama Y, Fukuda M. Genetic and biochemical investigations on bacterial catabolic pathways for lignin-derived aromatic compounds. Biosci Biotechnol Biochem. 2007;71:1-15.

6. McLeod MP, Warren RL, Hsiao WWL, Araki N, Myhre M, Fernandes C, et al. The complete genome of Rhodococcus sp. RHA1 provides insights into a catabolic powerhouse. PNAS. 2006;103:15582-7.

7. DeRito CM, Pumphrey GM, Madsen EL. Use of field-based stable isotope probing to identify adapted populations and track carbon flow through a phenol-degrading soil microbial community. Appl Environ Microbiol. 2005;71:7858-65

8. Geib SM, Filley TR, Hatcher PG, Hoover K, Carlson JE, Jimenez-Gasco Mdel M, et al. Lignin degradation in wood-feeding insects.Proc Natl Acad Sci U S A. 2008;105:12932-7.

9. Bugg TDH, Ahmad M, Hardiman EM, Rahmanpour R. Pathways for degradation of lignin in bacteria and fungi. Nat Prod Rep. 2011;28:1883-96.

10. Parton $W$ et al. Global-scale similarities in nitrogen release patterns during long-term decomposition. Science. 2007;315:361-4.

11. Silver WL, Lugo AE, Keller M. Soil oxygen availability and biogeochemistry along rainfall and topographic gradients in upland wet tropical forest soils. Biogeochemistry. 1999:44:301-28.

12. de Boer W, Folman LB, Summerbell RC, Boddy L. Living in a fungal world: impact of fungi on soil bacterial niche development $\star$. FEMS Microbiol Rev. 2005;29:795-811. 
13. Chandra R, Takeuchi H, Hasegawa T. Methane production from lignocellulosic agricultural crop wastes: a review in context to second generation of biofuel production. Renew Sust Energ Rev. 2012;16:1462-76.

14. Tschech A, Pfennig N. Growth yield increase linked to caffeate reduction in Acetobacterium woodii. Arch Microbiol. 1984;137:163-7.

15. Widdel F, Kohring GW, Mayer F. Studies on dissimilatory sulfate-reducing bacteria that decompose fatty acids. Arch Microbiol. 1983;134:286-94.

16. Janssen PH, Schuhmann A, Morschel E, Rainey FA. Novel anaerobic ultramicrobacteria belonging to the Verrucomicrobiales lineage of bacterial descent isolated by dilution culture from anoxic rice paddy soil. Appl Environ Microbiol. 1997;63:1382.

17. Wilson KH, Blitchington RB, Greene RC. Amplification of bacterial $16 \mathrm{~S}$ ribosomal DNA with polymerase chain reaction. J Clin Microbiol. 1990:28:1942-6.

18. Tatusov RL, Galperin MY, Natale DA, Koonin EV. The COG database: a tool for genome-scale analysis of protein functions and evolution. Nucleic Acids Res. 2000;28:33-6.

19. Field D, Garrity G, Gray T, Morrison N, Selengut J, Sterk P, et al. The minimum information about a genome sequence (MIGS) specification. Nat Biotechnol. 2008;26(5):541-7.

20. Bennett S. Solexa Ltd. Pharmacogenomics. 2004:5:433-8.

21. Li M, Copeland A, Han J. DUK-A fast and efficient Kmer based sequence matching tool. 2011. Available at: http://escholarship.org/uc/item/5cb5810k. pdf. Accessed September 18, 2013.

22. Gnerre S, MacCallum I, Przybylski D, Ribeiro FJ, Burton JN, Walker BJ, et al. High-quality draft assemblies of mammalian genomes from massively parallel sequence data. Proc Natl Acad Sci U S A. 2011;108:1513-8.

23. Hyatt D, Chen GL, Locascio PF, Land ML, Larimer FW, Hauser L. Prodigal: prokaryotic gene recognition and translation initiation site identification. BMC Bioinformatics. 2010;11:119.

24. Pati A, Ivanova NN, Mikhailova N, Ovchinnikova G, Hooper SD, Lykidis A, et al. GenePRIMP: a gene prediction improvement pipeline for prokaryotic genomes. Nat Meth. 2010;7:455-7

25. Lowe TM, Eddy SR. tRNAscan-SE: a program for improved detection of transfer RNA genes in genomic sequence. Nucl Acids Res. 1997;25:0955-64.

26. Pruesse E, Quast C, Knittel K, Fuchs BM, Ludwig W, Peplies J, et al. SILVA: a comprehensive online resource for quality checked and aligned ribosomal RNA sequence data compatible with ARB. Nucleic Acids Res. 2007;35:718896.

27. Nawrocki EP, Eddy SR. Infernal 1.1: 100-fold faster RNA homology searches. Bioinformatics. 2013;29:2933-5.

28. Markowitz VM, Chen I-MA, Palaniappan K, Chu K, Szeto E, Grechkin Y, et al. IMG: the Integrated Microbial Genomes database and comparative analysis system. Nucleic Acids Res. 2012;40:D115-22.

29. Markowitz VM, Mavromatis K, Ivanova NN, Chen I-MA, Chu K, Kyrpides NC. IMG ER: a system for microbial genome annotation expert review and curation. Bioinformatics. 2009;25:2271-8.

30. Gao F, Luo H, Zhang CT. DoriC 5.0: an updated database of oriC regions in both bacterial and archaeal genomes. Nucleic Acids Res. 2012;41:D90-3.

31. Zhang R, Zhang C-T. Multiple replication origins of the archaeon Halobacterium species NRC-1. Biochem Biophys Res Commun. 2003;302:728-34

32. Zhang $\mathrm{R}$, Zhang $\mathrm{C}-\mathrm{T}$. Identification of replication origins in archaeal genomes based on the Z-curve method. Archaea. 2005;1:335-46.

33. Gao F, Zhang C-T. Ori-Finder: a web-based system for finding oriCs in unannotated bacterial genomes. BMC Bioinformatics. 2008;9:79.

34. Wattam AR, Abraham D, Dalay O, Disz TL, Driscoll T, Gabbard JL, et al. PATRIC, the bacterial bioinformatics database and analysis resource. Nucl Acids Res. 2014;42(D1):D581-91. doi:10.1093/nar/gkt1099.

35. Goris J, Konstantinidis KT, Klappenbach JA, Coenye T, Vandamme P, Tiedje JM. DNA-DNA hybridization values and their relationship to whole-genome sequence similarities. Int J Syst Evol Microbiol. 2007:57:81-91.

36. Meier-Kolthoff JP, Auch AF, Klenk H-P, Göker M. Genome sequence-based species delimitation with confidence intervals and improved distance functions. BMC Bioinformatics. 2013;14:60.

37. Fischer-Romero C, Tindall BJ, Jüttner F. Tolumonas auensis gen. nov., sp. nov. , a toluene-producing bacterium from anoxic sediments of a freshwater lake. Int J Syst Bacteriol. 1996;46:183-8

38. Caldwell ME, Allen TD, Lawson PA, Tanner RS. Tolumonas osonensis sp. nov., isolated from anoxic freshwater sediment, and emended description of the genus Tolumonas. Int J Syst Evol Microbiol. 2011;61:2659-63.
39. Santamaría J, Toranzos GA. Enteric pathogens and soil: a short review. Int Microbiol. 2003;6:5-9.

40. DeAngelis KM, Sharma D, Varney R, Simmons B, Isern NG, Markilllie LM, et al. Evidence supporting dissimilatory and assimilatory lignin degradation in Enterobacter lignolytica SCF1. Front Microbiol. 2013;19;4:280.

41. Masai E, Katayama Y, Nishikawa S, Fukuda M. Characterization of Sphingomonas paucimobilis SYK-6 genes involved in degradation of ligninrelated compounds. J Ind Microbiol Biotechnol. 1999;23:364-73.

42. Harwood CS, Parales RE. The $\beta$-ketoadipate pathway and the biology of selfidentity. Annu Rev Microbiol. 1996;50:553-90.

43. Shi Y, , Chai L, Tang C, Yang Z, Zhang H, Chen R, et al. Characterization and genomic analysis of kraft lignin biodegradation by the betaproteobacterium Cupriavidus basilensis B-8. Biotechnol Biofuels. 2013;6:1.

44. DeAngelis KM, D'Haeseleer P, Chivian D, Fortney JL, Khudyakov J, Simmons $B$, et al. Complete genome sequence of 'Enterobacter lignolytica' SCF1. Stand Genomic Sci. 2011;5:69.

45. Woese CR, Kandler O, Wheelis ML. Towards a natural system of organisms: proposal for the domains Archaea, Bacteria, and Eucarya. Proc Natl Acad Sci U S A. 1990;87:4576-9.

46. Garrity GM, Lilburn TG, Cole JR, Harrison SH, Euzeby J, Tindall BJ. Introduction to the Taxonomic Outline of Bacteria and Archaea (TOBA) Release 7.7. The Taxonomic Outline of Bacteria and Archaea. 2007;7:1-5.

47. Garrity G, Bell J, Liburn T. Phylum XIV. Proteobacteria phyl. nov. In: Bergey's manual of systematic bacteriology, second edition, volume 2, part B. New York, NY USA: Springer; 2005

48. Garrity G, Bell J, Liburn T. Class III. Gammaproteobacteria class. nov. In: Bergey's manual of systematic bacteriology, second edition, volume 2, part B. New York, NY USA: Springer; 2005.

49. Martin-Carnahan A, Joseph SW. Order XII. Aeromonadales ord. nov. In: Bergey's manual of systematic bacteriology, second edition, volume 2, part B. New York, NY USA: Springer; 2005.

50. Martin-Carnahan A, Joseph SW. Family I. Aeromonadaceae. In: Bergey's manual of systematic bacteriology, second edition, volume 2, part B. New York, NY USA: Springer; 2005.

51. Fischer-Romero C, Tindall BJ. Genus incertae sedis III. Tolumonas. In: Bergey's manual of systematic bacteriology, second edition, volume 2, part B. New York, NY USA: Springer; 2005.

52. DeAngelis KM, Silver WL, Thompson AW, Firestone MK. Microbial communities acclimate to recurring changes in soil redox potential status. Environ Microbiol. 2010;12:3137-49.

53. Ashburner M, Ball CA, Blake JA, Botstein D, Butler H, Cherry JM, et al. Gene ontology: tool for the unification of biology. The Gene Ontology Consortium. Nat Genet. 2000;25(1):25-9.

54. Saitou N, Nei M. The neighbor-joining method: a new method for reconstructing phylogenetic trees. Mol Biol Evol. 1987;4:406-25.

55. Tamura K, Stecher G, Peterson D, Filipski A, Kumar S. MEGA6: Molecular Evolutionary Genetics Analysis Version 6.0. Mol Biol Evol. 2013;30:2725-9.

56. Felsenstein J. Confidence limits on phylogenies: an approach using the bootstrap. Evolution. 1985;39:783-91.

57. Jukes TH, Cantor CR. Evolution of protein molecules. In: Munro HN, editor. Mammalian protein metabolism. New York: Academic; 1969. p. 21-132.

58. Markowitz VM, Chen IM, Palaniappan K, Chu K, Szeto E, Grechkin Y, et al. IMG: the integrated microbial genomes database and comparative analysis system. Nucl Acids Res. 2012;40:D115-22.

\section{Submit your next manuscript to BioMed Central and take full advantage of:}

- Convenient online submission

- Thorough peer review

- No space constraints or color figure charges

- Immediate publication on acceptance

- Inclusion in PubMed, CAS, Scopus and Google Scholar

- Research which is freely available for redistribution 